\title{
Current Insights into the Potential Misuse of Platelet-based Applications for Doping in Sports
}

\author{
Authors \\ David Scully, Antonios Matsakas
}

\begin{abstract}
Affiliation
Hull York Medical School, Centre for Atherothrombotic and Metabolic Disease, Hull, United Kingdom of Great Britain and Northern Ireland
\end{abstract}

Key words

platelet-rich plasma, world anti-doping agency, prohibition list, growth factors, sports injury

accepted 25.03.2019

\section{Bibliography}

DOI https://doi.org/10.1055/a-0884-0734

Published online: 23.4.2019

Int J Sports Med 2019; 40: 427-433

(c) Georg Thieme Verlag KG Stuttgart · New York ISSN 0172-4622

\section{Correspondence}

Dr. Antonios Matsakas

Hull York Medical School,

Centre for Atherothrombotic \& Metabolic Disease, Molecular Physiology Laboratory, HU6 7RX Hull, United Kingdom of Great Britain and Northern Ireland, Tel.: + 44/148/2465 008, Fax: + 44/123/456 789

Antonios.Matsakas@hyms.ac.uk

\section{ABSTRACT}

Platelet-based applications are currently used for the delivery of growth factors and other biomolecules as autologous bio- materials in regenerative medicine and cosmetic therapies. Many studies have revealed that platelet-based applications such as platelet-rich plasma and platelet releasate exhibit beneficial biological effects after a sports injury or trauma when administered locally by intramuscular injections. At present, treatment of the public, patients and athletes with plateletbased applications is permitted and regulated by the Food and Drug Administration and the World Anti-Doping Agency. Since 2011 the use of autologous platelet-rich plasma is permitted in competitive sports by the World Anti-Doping Agency, due to the lack of evidence in performance enhancement and anabolic effects. However, accumulating research has recently shed light on the role of platelet-derived growth factors in wound healing, skeletal myogenesis, muscle stem cell function and tissue regeneration. Although any ergogenic potential of platelet-rich plasma and platelet releasate on intact skeletal muscle and human sports performance remain to be established, novel evidence suggests that platelet-derived growth factors can modulate muscle, tendon, ligament, protein synthesis/degradation, vascularization, energy utilization and regenerative capacity in various experimental settings. Since platelet-based applications are currently not prohibited, they constitute a tool for potential abuse and doping in sports. The aim of this review is to critically discuss and assimilate current insights and biological evidence that set the ground for exploitation and misuse in competitive sports, and develop strategies to combat these activities.

\section{Introduction}

There has been much debate in recent scientific literature both for and against the notion that there is an advantageous use of platelet-based applications in musculoskeletal adaptations [1-9]. The reason this particular application has attracted such consideration relates to the experimental evidence both in vitro and in vivo showing promising benefits for skeletal muscle recovery after injury [10-14]. However, the use of platelet-based applications fails to consistently translate to positive results in clinical trials, especially for skeletal muscle injuries [5, 15-17]. Studies now suggest that the discrepancy in the literature may, at least in part, be due to the differing preparation methods between laboratories and the clinical setting [1, 9]. Beyond the potential benefits of platelets as biomaterials for therapeutic purposes, it has previously been speculated that at least 86,000 athletes in the United States have used platelet-rich plasma injections annually [18].

In 2011, the World Anti-Doping Agency (WADA) removed autologous platelet-rich plasma (PRP) for skeletal muscle, tendon and ligament injections from the prohibition list due to the lack of convincing evidence regarding its performance enhancing and anabolic effects. The WADA's current stance on the status of plateletderived preparations is that PRP does not exhibit any potential for performance augmentation other than a possible therapeutic effect. Despite the presence of variable cytokines and growth factors 
in platelet-derived preparations, they were removed from the prohibition list.

In the WADA prohibition lists from 2010-2018 (i. e., section 2 regarding peptide hormones, growth factors and related substances), the agency declared a prohibition against the individual growth factors: "Growth Hormone, Insulin-like Growth Factor-1, Fibroblast Growth Factors, Hepatocyte Growth Factor, Mechano-growth Factors, Platelet-derived Growth Factor, Vascular-endothelial Growth Factor." Interestingly, WADA continued stating that "any other growth factor affecting muscle, tendon or ligament protein synthesis/degradation, vascularization, energy utilization, regenerative capacity or fiber type switching; and other substances with similar chemical structure or similar biological effect(s)" are also prohibited. This was followed in the same section from 2010 by a prohibition against “Platelet-derived preparations (e.g., platelet-rich plasma, 'blood spinning') administered by intramuscular route" for competing athletes $[19,20]$. However, several of these individual growth factors are found in high concentrations in platelet releasates and are still on the WADA's prohibition list when administered independently as refined constituents [14, 19, 21].

Due to the fact that the majority of the above-mentioned growth factors are contained in platelet releasate, the aim of this review is to provide current insights in the potential abuse of platelet-based applications in competitive sports. We also aim to determine whether there is any merit to consider re-establishing PRP and analogues as performance enhancing applications [22]. The use of PRP and various other platelet-based applications such as platelet releasate (defined as an acellular preparation of platelet granule secretions after aggregation) have been shown to be beneficial in skeletal muscle injury models [10-12, 14, 15, 23-32]. For this reason, this review will focus on the 2011 WADA statement that "any growth factors affecting muscle, tendon or ligament protein synthesis/degradation, vascularization, energy utilization, regenerative capacity and other substances with similar chemical structure or similar biological effect(s)" are prohibited by athletes, and that platelet-based applications may be re-established in this category.

A PubMed search was conducted to identify articles by using any of the following terms: platelet-rich plasma, platelet releasate, doping, skeletal muscle, sports performance, athletes, growth factors. Scientific literature was reviewed to identify recent evidence about platelet-based applications and their effects on the human body taking into account relevant experimental evidence. Data from original research papers discussed in this review were collected in accordance with the Journal's Ethical Standards [33].

\section{Can platelet-based applications be exploited to improve sports performance?}

A study determined the effect of a single intramuscular injection of autologous conditioned plasma on the levels of circulating cytokines and growth factors banned by the WADA, in the blood of the recipients [34]. This study determined that among the levels of Insulin Like Growth Factor-1 (IGF-1), Endothelial Growth Factor-1 (EGF-1), Platelet-Derived Growth Factor-AB, -BB (PDGF-AB, -BB), Fibroblast Growth Factor (FGF), Vascular-Endothelial Growth Factor-1 (VEGF-1) and Transforming Growth Factor-B1, or -B2 (TGF$B 1,-B 2)$, only TGF-B2 showed a significant increase in circulating blood $3 \mathrm{~h}$ and $24 \mathrm{~h}$ post-injection. This may increase the potential for fibrosis according to the authors. If intramuscular injections of PRP do not increase banned substances in the circulatory system, this impedes methods of anti-doping detection. Unlike blood doping, however, platelet-based applications are autologous, and are supposed unlikely to be ergogenic [35]. One may argue that concentrating a substance (e. g., PRP) by removal, refinement and reintroduction to a specific location, such as intramuscular injections, may augment tissue function without being detected in the circulatory system.

Opinions regarding the removal of PRP from the WADA prohibition list have been expressed in detail previously [36, 37]. It has been argued that the unbound half-life of IGF-1 ( $10 \mathrm{~min}$ ) would not be able to exert systemic effects, and therefore, any potential benefits are limited to the area of injection. The same study also states that the concentration of IGF- 1 has to be 500 times higher than that found in PRP, in order to exert systemic anabolic effects [36]. However, direct evidence that platelet-based applications are ergogenic in uninjured skeletal muscle is still lacking, providing further grounds for the removal of PRP from the WADA prohibition list in $2011[19,37]$. A later publication looked at the systemic effects of PRP in circulation after intra-tendinous injections, using similar PRP preparation methods as Creaney and Hamilton in 2008. This study reported that increased levels of the constituents banned by WADA were detected systemically after injection of PRP $[18,19]$. In fact, serum IGF-1, VEGF, and bFGF levels were significantly elevated after PRP injection, associated with an ergogenic effect of PRP, exclaiming that VEGF could be used as a potential marker for PRP doping.

It is important to emphasize the fact that taking PRP off the prohibition list does not restrict the athletes from using higher concentrations of platelet-released growth factors and applying them more frequently. Yet there was previously no standardized clinical preparation method for PRP, indicating that the system is susceptible to being abused in the context of sports performance. Moreover, additional platelet-based applications can be utilized, such as platelet releasate, platelet lysate, platelet-rich fibrin, leukocyte-rich PRP to further customize and optimize the preparation of PRP for use in athletic competition. Previous studies have attempted to customize PRP for further benefits in skeletal muscle recovery, such that by removing TGF- $\beta$ may alleviate fibrosis and inflammation [38]. Furthermore, we have recently shown that platelet releasate increases the proliferation of myoblasts with a linear correlation to the concentration of platelets used [14]. However, the impact of platelet releasate in muscle stem cell function and myogenesis in highly trained, healthy individuals such as athletes remains to be determined.

\section{Recent evidence for platelet-based applications to remodel skeletal muscle and potentially increase sports performance}

There has been recent robust evidence that platelet-based applications positively affect myoblast proliferation, early inflammatory response, myogenic regulatory factors, regeneration time and muscle fiber hypertrophy with a decrease in pain, claudication score, oxidative stress and time-to recovery $[10-12,15,17,23-$ 28, 30-32, 38-45]. In particular, platelet releasate has been shown by independent groups to increase skeletal muscle regeneration 
in vivo $[14,32,45]$. This supports the notion that the positive effect on skeletal muscle is derived from platelet granule secretions as opposed to the plasma or cell-to-cell contact. With this being the case, the potential to concentrate the growth factors and increase the dose in an autologous or allogeneic manner is a matter of concern that could be abused by athletes. Growth factors directly derived from platelet-based applications are known to affect other tissues and this is in conflict with the WADA statement that prohibits the use of "any growth factor(s) affecting muscle, tendon or ligament protein synthesis/degradation, vascularization, energy utilization, regenerative capacity." As outlined in previous papers, platelet-based applications affect tendon and skeletal muscle tissue ( Fig. 1) and cellular vascularization, regenerative capacity and protein synthesis and skeletal muscle energy utilization $[9,10,14$, $40,45,48,51,52]$.

The main argument against using platelet-based applications is typically due to the lack of detectable growth factors in the circulatory system after intramuscular injection [36]. Although this is a prominent argument whereby platelet-based applications may lack systemic effects; the experimental evidence suggests that a localized injection through ultrasound guidance is quite effective at re- generation $[53,54]$. It is indeed important to speed up recovery and injury in sports and orthopedics; however, the major lacking evidence is the effect on uninjured skeletal muscle. Moreover, in vivo studies looking at non-regenerating myofibers remain to be conducted to obtain a better understanding whether plateletbased applications are effective at increasing performance. Additionally, platelet concentration typically takes up to 7 days to return to baseline in the blood after donation with prolonged storage of platelet releasate, supra-physiological levels of growth factors can be achieved [55].

Interestingly, one study looking at uninjured skeletal muscles from racing horses showed an increase in embryonic and type I myosin heavy chain mRNA expression two and seven days after PRP injection, respectively [56]. Whether this can be translated to muscle fiber growth or hyperplasia was not examined in that particular study, and the physiological significance of this finding remains to be established. To the best of our knowledge, this is the only report we could identify on PubMed injecting PRP into intact muscle, where a potentially beneficial effect was observed.

A recent article has shown how application of platelet releasate can alter skeletal muscle stem cell fate and drive myogenesis [14].

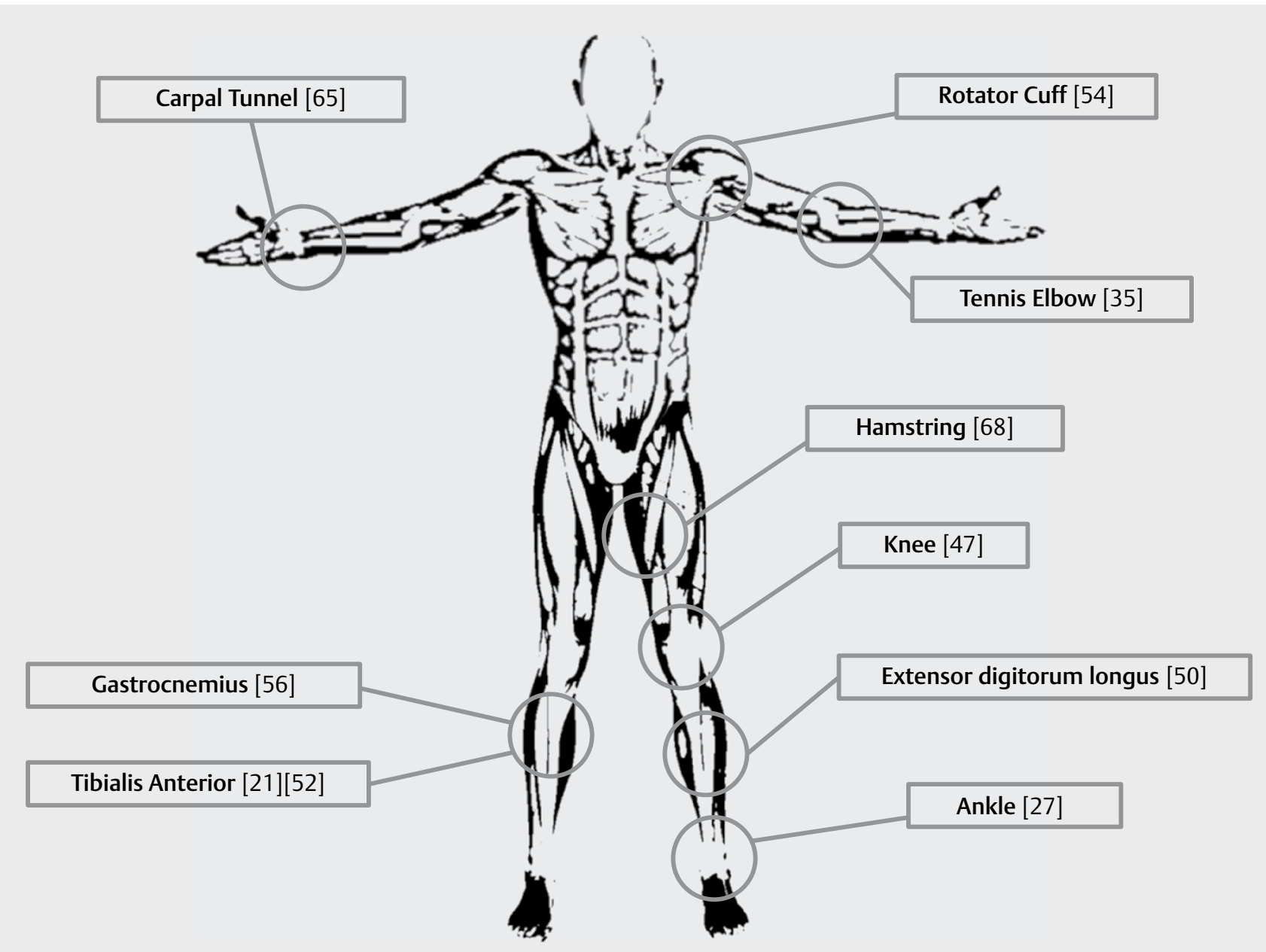

- Fig. 1 Illustration shows clinical and pre-clinical evidence for the beneficial effects of platelet-based applications on different areas of the body for tendon, ligament and skeletal muscle regeneration. Based on data from multiple sources [14, 25, 31, 32, 35, 46-50]. 
Myogenic regulatory factors such as MyoD expression have been shown to be altered on myofibers from mice ex vivo after platelet releasate application in a dose-dependent manner $[11,14]$. Both Pax7 and MyoD are important markers for skeletal muscle stem cells. Pax7 is expressed in quiescent and activated cells; however, MyoD is expressed in activated and proliferating cells [57]. Loss of Pax7 in MyoD-positive cells is seen after application of platelet releasate, causing an enhanced commitment to differentiation, without sacrificing the pool of Pax7-positive stem cells returning to quiescence $[11,14]$. Since regular exercise training drives skeletal muscle functional adaptations by regulating muscle stem cell function, the above recent findings raise concerns about the WADA 2018 prohibition list on peptide hormones, growth factors, related substances, and mimetics and potential abuse in sports [58, 59]. However, it becomes apparent that further studies into intact muscle in vivo need to be carried out before any assumption can be made about whether platelet-based applications are beneficial for athletes.

\section{The Food and Drug Administration's stance on platelet-based applications}

Although platelet-based applications are not on the United States' Food and Drug Administration's (FDA) banned substance list, there are rules and regulations for commercially using them cosmetically and therapeutically. In terms of PRP for sports-related or therapeutic augmentations, there are many legalities regarding their use. Clinicians are therefore made to maintain records of use and effects, hold a biologics license, and keep up-to-date with current evidence in the field [60]. These restrictions, in turn, help regulate safety and consistency, and keep record of PRP procedures. PRP is considered a "biologic," or biological product by the FDA. Biologics are regulated by the FDA's center for biologics evaluation and research. However, the use of autologous growth factors had not been specifically considered by WADA prior to $2010[35,61]$. The ability, however difficult and expensive, to currently treat the public, patients and athletes with PRP and platelet-rich products is perfectly acceptable under FDA and WADA regulations. This leaves the possibility for the application of concentrated supra-physiological platelet-based applications, or frequently used intramuscular injections to be potentially abused. Supra-physiological levels of platelets used to make platelet releasate have recently been shown to dose-dependently upregulate myoblast proliferation in vitro, which may contribute to a faster recovery after training or exercise, similar to anabolics [14].

\section{Safety of platelet-based applications for use by athletes}

Despite the plausible potential for athletes to abuse platelet-based applications to manipulate sports performance, another crucial factor to consider is the safety of application. There is currently increasing evidence in the literature as to whether platelet-based applications affect cellular senescence, apoptosis, reactive oxygen species and mutagenesis. Some promising articles addressing these aspects show a reduction in apoptosis of in vivo injured skeletal muscle [32]. Similarly, cellular survival has been shown to be increased with platelet-based applications in vitro[44]. Plateletbased applications are known to be pro-proliferative in many tissues and to induce angiogenesis, which has sparked interest in their effects on cancers. It has recently been shown that platelet releasate promotes breast cancer growth and angiogenesis via VEGF signaling [62]. In fact, platelets are known to drive cellular proliferative signals, cell survival, metastasis and angiogenesis [63]. This microenvironment may be potentially harmful in already existing cancers; however, platelet-based applications are argued to be autologous and non-harmful as they do not induce mutagenesis [64]. On the other hand, clinical trials report an effective and safe outcome to using platelet-based applications for multiple treatments with no observed side effects [15, 17, 41, 50, 65]. Additionally, allogeneic platelet-rich plasma has recently been deemed safe for osteoarthritis patients according to a human pilot study [66]. This suggests that PRP may be a safe treatment even if non-autologous, although this remains to be established in large scale studies. At present, the WADA does not distinguish between the use of autologous and allogeneic PRP [67]. Subsequently, a potential route towards performance manipulation cannot be ruled out, such that master-class athletes are currently not restricted from using allogenic platelet-rich plasma from young athletes [67]. A recent study has established a differential profile of platelet-rich plasma-contained growth factors among individuals in terms of age and sex, showing higher levels of growth factors (e. g., IGF-1) and lower levels of inflammatory and fibrosis-inducing cytokines (e. g., TGF- $\beta$ ) in young males [68]. Consequently, with allogeneic PRP becoming a safe and viable option for patient treatment, and no ban on its use in athletes, the risk of exploitation is not prohibited.

To date, there is a noticeable difficulty of testing for autologous platelet-based applications. Potential PRP involvement in altering the biological passport of an athlete could be a way of detecting platelet-related abuse in sporting applications, but remains to be established. The option for athletes to use their own platelets' innate ability to induce regeneration is receiving clinical attention and could potentially be already exploited for performance manipulation [18]. Similarly, allogeneic platelet-based applications constitute a new therapeutic tool for several diseases that can be enriched by recombinant growth factors, and their abuse in sports is unavoidable [67].

\section{Conclusion}

In this review, we aimed to discuss current insights and biological evidence that set the ground for exploitation and misuse in competitive sports. In addition, we provided reasoning that may help to develop strategies to combat these activities. With studies reporting no increase in systemic levels of growth factors in the blood after intra-muscular PRP injections, there is reasonable merit to not consider PRP a banned substance. However, with more recent studies emerging, additional consideration needs to be deliberated, such as manipulation, customization and concentration of PRP preparation methods that can be abused by athletes. Allogeneic applications from healthier and younger individuals that were overlooked previously in terms of performance manipulation may require re-evaluation. The 2011-2018 WADA prohibition lists declare that any substance that increases muscle, tendon or ligament protein synthesis/degradation, vascularization, energy utilization or regenerative capacity is banned. As current evidence has shown that such methods strongly impact skeletal muscle, tendon, liga- 
ment and orthopedics in terms of regeneration and potential for sports performance, the risk of abuse of platelet-based applications remains valid.

\section{Future Perspectives}

There is limited evidence on whether platelet-based applications can improve sports performance and reprogram skeletal muscle transcriptional signature in healthy, non-injured individuals. Therefore, more studies are needed to assess experimentally whether such platelet-based approaches are able to improve muscle strength, increase muscle mass, increase endurance, increase athletic performance, affect recovery time, affect protein synthesis, and/or alter redox homeostasis. To this aim, it is essential to establish and further develop techniques in order to detect abuse of platelet-based applications in competitive sports. For example, VEGF has been previously suggested as a marker for PRP doping in the blood [18].

Knowledge in the field of platelet-based applications affecting skeletal muscle, ligament and tendon is continuously accumulating. Despite the absence of direct evidence linking platelet applications with increased sports performance, current evidence suggests that platelet-rich plasma drives skeletal myogenesis in vitro, ex vivo and accelerates regeneration in vivo. This falls within the current doping definition regarding manipulations of regenerative capacity and begs the question whether platelet-based applications have to be reconsidered as prohibited substances or methods in competitive sports.

\section{Acknowledgements}

AM's work has been supported by the European Union (Grant: FP7PEOPLE-PCIG14-GA-2013-631440, 2014-2018). DS was funded by the Hull York Medical School through the University of Hull PhD Studentships Programme.

\section{Conflict of Interest}

Authors declare that they have no conflict of interest.

\section{References}

[1] Andia I, Abate M. Platelet-rich plasma: Combinational treatment modalities for musculoskeletal conditions. Front Med 2018; 12: 139-152

[2] Brossi PM, Moreira J], Machado TS, Baccarin RY. Platelet-rich plasma in orthopedic therapy: A comparative systematic review of clinical and experimental data in equine and human musculoskeletal lesions. BMC Vet Res 2015; 11: 98

[3] Lee KS, Wilson J], Rabago DP, Baer GS, Jacobson JA, Borrero CG. Musculoskeletal applications of platelet-rich plasma: Fad or future? AJR Am J Roentgenol 2011; 196: 628-636

[4] McClure M], Garg K, Simpson DG, Ryan J], Sell SA, Bowlin GL, Ericksen JJ. The influence of platelet-rich plasma on myogenic differentiation. J Tissue Eng Regen Med 2016; 10: E239-E249
[5] Mosca M], Rodeo SA. Platelet-rich plasma for muscle injuries: Game over or time out? Curr Rev Musculoskelet Med 2015; 8: 145-153

[6] Navani A, Li G, Chrystal J. Platelet rich plasma in musculoskeletal pathology: a necessary rescue or a lost cause? Pain Physician 2017; 20: E345-E356

[7] Nguyen RT, Borg-Stein J, Mclnnis K. Applications of platelet-rich plasma in musculoskeletal and sports medicine: An evidence-based approach. PM R 2011; 3: 226-250

[8] Sánchez M, Anitua E, Delgado D, Sánchez P, Orive G, Padilla S. Muscle repair: Platelet-rich plasma derivates as a bridge from spontaneity to intervention. Injury 2014; 45: S7-S14

[9] Scully D, Naseem KM, Matsakas A. Platelet biology in regenerative medicine of skeletal muscle. Acta Physiol (Oxf) 2018; 223: e13071

[10] Dimauro I, Grasso L, Fittipaldi S, Fantini C, Mercatelli N, Racca S, Geuna S, Di Gianfrancesco A, Caporossi D, Pigozzi F, Borrione P. Platelet-rich plasma and skeletal muscle healing: A molecular analysis of the early phases of the regeneration process in an experimental animal model. PLoS One 2014; 9: e102993

[11] Li H, Hicks J], Wang L, Oyster N, Philippon MJ, Hurwitz S, Hogan MV, Huard J. Customized platelet-rich plasma with transforming growth factor beta1 neutralization antibody to reduce fibrosis in skeletal muscle. Biomaterials 2016; 87: 147-156

[12] Li H, Usas A, Poddar M, Chen CW, Thompson S, Ahani B, Cummins ], Lavasani M, Huard J. Platelet-rich plasma promotes the proliferation of human muscle derived progenitor cells and maintains their stemness. PLoS One 2013; 8: e64923

[13] Saury C, Lardenois A, Schleder C, Leroux I, Lieubeau B, David L, Charrier M, Guevel L, Viau S, Delorme B, Rouger K. Human serum and platelet lysate are appropriate xeno-free alternatives for clinical-grade production of human MuStem cell batches. Stem Cell Res Ther 2018; 9: 128

[14] Scully D, Sfyri P, Verpoorten S, Papadopoulos P, Munoz-Turrillas MC, Mitchell R, Aburima A, Patel K, Gutierez L, Naseem KM, Matsakas A. Platelet releasate promotes skeletal myogenesis by increasing muscle stem cell commitment to differentiation and accelerates muscle regeneration following acute injury. Acta Physiol (Oxf) 2019; 225: e13207

[15] Bernuzzi G, Petraglia F, Pedrini MF, De Filippo M, Pogliacomi F, Verdano MA, Costantino C. Use of platelet-rich plasma in the care of sports injuries: Our experience with ultrasound-guided injection. Blood Transfus 2014; 12: (Suppl 1): s229-s234

[16] Rettig AC, Meyer S, Bhadra AK. Platelet-rich plasma in addition to rehabilitation for acute hamstring injuries in NFL players: Clinical effects and time to return to play. Orthop J Sports Med 2013; 1 : 2325967113494354

[17] Wetzel RJ, Patel RM, Terry MA. Platelet-rich plasma as an effective treatment for proximal hamstring injuries. Orthopedics 2013; 36: e64-e70

[18] Wasterlain AS, Braun HJ, Harris AH, Kim HJ, Dragoo JL. The systemic effects of platelet-rich plasma injection. Am J Sports Med 2013; 41: 186-193

[19] WADA. World Anti-Doping Code.In Available from https://www. wada-ama.org/sites/default/files/resources/files/WADA_Prohibited_ List_2010_EN.pdf World Anti-Doping Agency, Montreal; World Anti-Doping Agency 2010 accessed on 23/11/2018

[20] WADA. World Anti-Doping Code.In Available from https://www. wada-ama.org/sites/default/files/resources/files/WADA_Prohibited_ List_2011_EN.pdf World Anti-Doping Agency, Montreal; World Anti-Doping Agency 2011 accessed on 23/11/2018

[21] Wijten P, van Holten T, Woo LL, Bleijerveld OB, Roest M, Heck A], Scholten $A$. High precision platelet releasate definition by quantitative reversed protein profiling-brief report. Arterioscler Thromb Vasc Biol 2013; 33: 1635-1638 
[22] Burkhart JM, Vaudel M, Gambaryan S, Radau S, Walter U, Martens L, Geiger J, Sickmann A, Zahedi RP. The first comprehensive and quantitative analysis of human platelet protein composition allows the comparative analysis of structural and functional pathways. Blood 2012; 120: e73-e82

[23] Borrione P, Gianfrancesco AD, Pereira MT, Pigozzi F. Platelet-rich plasma in muscle healing. Am J Phys Med Rehabil 2010; 89: 854-861

[24] Denapoli PM, Stilhano RS, Ingham SJ, Han SW, Abdalla RJ. Platelet-Rich Plasma in a Murine Model: Leukocytes, Growth Factors, Flt-1, and Muscle Healing. Am J Sports Med 2016; 44: 1962-1971

[25] Hammond JW, Hinton RY, Curl LA, Muriel JM, Lovering RM. Use of autologous platelet-rich plasma to treat muscle strain injuries. Am J Sports Med 2009; 37: 1135-1142

[26] Huang S, Wang Z. Platelet-rich plasma-derived growth factors promote osteogenic differentiation of rat muscle satellite cells: In vitro and in vivo studies. Cell Biol Int 2012; 36: 1195-1205

[27] Im W, Ban J], Lim J, Lee M, Chung JY, Bhattacharya R, Kim SH. Adipose-derived stem cells extract has a proliferative effect on myogenic progenitors. In Vitro Cell Dev Biol Anim 2014; 50: 740-746

[28] Martins RP, Hartmann DD, de Moraes JP, Soares FA, Puntel GO. Platelet-rich plasma reduces the oxidative damage determined by a skeletal muscle contusion in rats. Platelets 2016; 27: 784-790

[29] Notodihardjo PV, Morimoto N, Kakudo N, Matsui M, Sakamoto M, Liem PH, Suzuki K, Tabata Y, Kusumoto K. Gelatin hydrogel impregnated with platelet-rich plasma releasate promotes angiogenesis and wound healing in murine model. J Artif Organs 2015; 18: 64-71

[30] Pinheiro CL, Peixinho CC, Esposito CC, Manso JE, Machado JC. Ultrasound biomicroscopy and claudication test for in vivo follow-up of muscle repair enhancement based on platelet-rich plasma therapy in a rat model of gastrocnemius laceration. Acta Cir Bras 2016; 31: 103-110

[31] Takase F, Inui A, Mifune Y, Sakata R, Muto T, Harada Y, Ueda Y, Kokubu T, Kurosaka M. Effect of platelet-rich plasma on degeneration change of rotator cuff muscles: In vitro and in vivo evaluations. J Orthop Res 2017; 35: 1806-1815

[32] Tsai WC, Yu TY, Chang G], Lin LP, Lin MS, Pang JS. Platelet-Rich Plasma Releasate Promotes Regeneration and Decreases Inflammation and Apoptosis of Injured Skeletal Muscle. Am J Sports Med 2018; 46: 1980-1986

[33] Harriss D], Macsween A, Atkinson G. Standards for ethics in sport and exercise science research: 2018 Update. Int J Sports Med 2017; 38: $1126-1131$

[34] Schippinger G, Fankhauser F, Oettl K, Spirk S, Hofmann P. Does single intramuscular application of autologous conditioned plasma influence systemic circulating growth factors? J Sports Sci Med 2012; 11: 551-556

[35] Mishra A, Harmon K, Woodall J, Vieira A. Sports medicine applications of platelet rich plasma. Curr Pharm Biotechnol 2012; 13: 1185-1195

[36] Creaney L, Hamilton B. Growth factor delivery methods in the management of sports injuries: The state of play. $\mathrm{Br}$ ] Sports Med 2008; 42: 314-320

[37] Engebretsen L, Steffen K, Alsousou ], Anitua E, Bachl N, Devilee R, Everts P, Hamilton B, Huard J, Jenoure P, Kelberine F, Kon E, Maffulli N, Matheson G, Mei-Dan O, Menetrey J, Philippon M, Randelli P, Schamasch P, Schwellnus M, Vernec A, Verrall G. IOC consensus paper on the use of platelet-rich plasma in sports medicine. Br J Sports Med 2010; 44: 1072-1081

[38] Miroshnychenko O, Chang WT, Dragoo JL. The use of platelet-rich and platelet-poor plasma to enhance differentiation of skeletal myoblasts: Implications for the use of autologous blood products for muscle regeneration. Am J Sports Med 2017; 45: 945-953

[39] Borrione P, Fossati C, Pereira MT, Giannini S, Davico M, Minganti C, Pigozzi F. The use of platelet-rich plasma (PRP) in the treatment of gastrocnemius strains: A retrospective observational study. Platelets 2018; 29: 596-601
[40] Borrione P, Grasso L, Chierto E, Geuna S, Racca S, Abbadessa G, Ronchi G, Faiola F, Di Gianfrancesco A, Pigozzi F. Experimental model for the study of the effects of platelet-rich plasma on the early phases of muscle healing. Blood Transfus 2014; 12: (Suppl 1): s221-s228

[41] Bubnov R. Ultrasound guided injections of Platelets Rich Plasma for muscle injury in professional athletes. Comparative study. Med Ultrason 2013; 15: 101-105

[42] Sassoli C, Frati A, Tani A, Anderloni G, Pierucci F, Matteini F, Chellini F, Zecchi Orlandini S, Formigli L, Meacci E. Mesenchymal stromal cell secreted sphingosine 1-phosphate (S1P) exerts a stimulatory effect on skeletal myoblast proliferation. PLoS One 2014; 9: e108662

[43] Sassoli C, Pini A, Chellini F, Mazzanti B, Nistri S, Nosi D, Saccardi R, Quercioli F, Zecchi-Orlandini S, Formigli L. Bone marrow mesenchymal stromal cells stimulate skeletal myoblast proliferation through the paracrine release of VEGF. PLoS One 2012; 7: e37512

[44] Sassoli C, Vallone L, Tani A, Chellini F, Nosi D, Zecchi-Orlandini S. Combined use of bone marrow-derived mesenchymal stromal cells (BM-MSCs) and platelet rich plasma (PRP) stimulates proliferation and differentiation of myoblasts in vitro: New therapeutic perspectives for skeletal muscle repair/regeneration. Cell Tissue Res 2018; 372: 549-570

[45] Tsai WC, Yu TY, Lin LP, Lin MS, Wu YC, Liao CH, Pang JS. Platelet rich plasma releasate promotes proliferation of skeletal muscle cells in association with upregulation of PCNA, cyclins and cyclin dependent kinases. Platelets 2017; 28: 491-497

[46] Laver L, Carmont MR, McConkey MO, Palmanovich E, Yaacobi E, Mann G, Nyska M, Kots E, Mei-Dan O. Plasma rich in growth factors (PRGF) as a treatment for high ankle sprain in elite athletes: $\mathrm{A}$ randomized control trial. Knee Surg Sports Traumatol Arthrosc 2015; 23: 3383-3392

[47] Saturveithan C, Premganesh G, Fakhrizzaki S, Mahathir M, Karuna K, Rauf K, William H, Akmal H, Sivapathasundaram N, Jaspreet K. Intra-articular hyaluronic acid (HA) and platelet rich plasma (PRP) injection versus hyaluronic acid $(\mathrm{HA})$ injection alone in patients with grade III and IV knee osteoarthritis (OA): a retrospective study on functional outcome. Malays Orthop J 2016; 10: 35-40

[48] Schnabel LV, Mohammed HO, Miller BJ, McDermott WG, Jacobson MS, Santangelo KS, Fortier LA. Platelet rich plasma (PRP) enhances anabolic gene expression patterns in flexor digitorum superficialis tendons. J Orthop Res 2007; 25: 230-240

[49] Wu YT, Ho TY, Chou YC, Ke M], Li TY, Huang GS, Chen LC. Six-month efficacy of platelet-rich plasma for carpal tunnel syndrome: A prospective randomized, single-blind controlled trial. Sci Rep 2017; 7: 94

[50] Zanon G, Combi F, Combi A, Perticarini L, Sammarchi L, Benazzo F. Platelet-rich plasma in the treatment of acute hamstring injuries in professional football players. Joints 2016; 4: 17-23

[51] Arslan E, Nellesen T, Bayer A, Prescher A, Lippross S, Nebelung S, Jahr $\mathrm{H}$, Jaeger $\mathrm{C}$, Huebner WD, Fischer $\mathrm{H}$, Stoffel M, Shakibaei M, Pufe T, Tohidnezhad M. Effect of platelet mediator concentrate (PMC) on Achilles tenocytes: an in vitro study. BMC Musculoskelet Disord 2016; 17: 307

[52] Virchenko O, Grenegard M, Aspenberg P. Independent and additive stimulation of tendon repair by thrombin and platelets. Acta Orthop 2006; 77: 960-966

[53] Davidson J, Jayaraman S. Guided interventions in musculoskeletal ultrasound: what's the evidence? Clin Radiol 2011; 66: 140-152

[54] Sengodan VC, Kurian S, Ramasamy R. Treatment of partial rotator cuff tear with ultrasound-guided platelet-rich plasma. J Clin Imaging Sci 2017; 7: 32

[55] Thokala RP, Radhakrishnan K, Anandan A, Panicker VK. Recovery of platelet count among apheresis platelet donors. J Clin Diagn Res 2016; 10: EC01-EC04 
[56] Fukuda K, Miyata H, Kuwano A, Kuroda T, Tamura N, Kotoyori Y, Kasashima Y. Does the injection of platelet-rich plasma induce changes in the gene expression and morphology of intact Thoroughbred skeletal muscle? J Equine Sci 2017; 28: 31-39

[57] Zammit PS, Golding JP, Nagata Y, Hudon V, Partridge TA, Beauchamp JR. Muscle satellite cells adopt divergent fates: a mechanism for self-renewal? J Cell Biol 2004; 166: 347-357

[58] Kadi F, Charifi N, Denis C, Lexell J, Andersen JL, Schjerling P, Olsen S, Kjaer M. The behaviour of satellite cells in response to exercise: What have we learned from human studies? Pflugers Arch 2005; 451: 319-327

[59] WADA. World Anti-Doping Code. In, World Anti-Doping Agency, Montreal.Available from https://www.wada-ama.org/sites/default/ files/prohibited_list_2018_en.pdf World Anti-Doping Agency 2018 accessed on 23/11/2018

[60] Beitzel K, Allen D, Apostolakos ], Russell RP, McCarthy MB, Gallo G], Cote MP, Mazzocca AD. US definitions, current use, and FDA stance on use of platelet-rich plasma in sports medicine. J Knee Surg 2015; 28: 29-34

[61] Bachl N, Derman W, Engebretsen L, Goldspink G, Kinzlbauer M, Tschan H, Volpi P, Venter D, Wessner B. Therapeutic use of growth factors in the musculoskeletal system in sports-related injuries. J Sports Med Phys Fitness 2009; 49: 346-357
[62] Jiang L, Luan Y, Miao X, Sun C, Li K, Huang Z, Xu D, Zhang M, Kong F, $\mathrm{Li}$ N. Platelet releasate promotes breast cancer growth and angiogenesis via VEGF-integrin cooperative signalling. $\mathrm{Br}$ J Cancer 2017; 117: 695-703

[63] Franco AT, Corken A, Ware J. Platelets at the interface of thrombosis, inflammation, and cancer. Blood 2015; 126: 582-588

[64] Salamanna F, Veronesi F, Maglio M, Della Bella E, Sartori M, Fini M. New and emerging strategies in platelet-rich plasma application in musculoskeletal regenerative procedures: General overview on still open questions and outlook. Biomed Res Int 2015; 2015: 846045

[65] Le ADK, Enweze L, DeBaun MR, Dragoo JL. Current Clinical Recommendations for Use of Platelet-Rich Plasma. Curr Rev Musculoskelet Med 2018; 11: 624-634

[66] Bottegoni C, Dei Giudici L, Salvemini S, Chiurazzi E, Bencivenga R, Gigante A. Homologous platelet-rich plasma for the treatment of knee osteoarthritis in selected elderly patients: An open-label, uncontrolled, pilot study. Ther Adv Musculoskelet Dis 2016; 8: 35-41

[67] Anitua E, Prado R, Orive G. Allogeneic platelet-rich plasma: At the dawn of an off-the-shelf therapy? Trends Biotechnol 2017; 35: 91-93

[68] Xiong G, Lingampalli N, Koltsov JCB, Leung LL, Bhutani N, Robinson WH, Chu CR. Men and women differ in the biochemical composition of platelet-rich plasma. Am J Sports Med 2018; 46: 409-419 